\title{
Força militar dos EUA no pós-guerra fria: ganhando batalhas e perdendo guerras
}

\author{
USA's military force in post-Cold War: \\ winning battles and losing wars
}

Rev. Bra. Est. Def. v. 3, nº 2, jul./dez. 2016, p. 103-117

ISSN 2358-3932

\section{HUMBERTO JOSÉ LOURENÇÃO LUIS EDUARDO POMBO CELLES CORDEIRO}

\section{INTRODUÇÃO}

O presente artigo analisa, com as lições extraídas dos fracassos da Guerra do Vietnã e do resgate de reféns, a evolução do emprego de força militar dos Estados Unidos no período entre a década de 1980 e os dias atuais. A escolha dos EUA como objeto de análise se justifica na medida em que eles ainda são a maior potência militar do mundo, líderes da maior aliança militar existente (OTAN) e com presença em um grande número de países ao redor do planeta. Devido a essa posição, tendem a servir de modelo doutrinário para uma grande maioria de aliados, bem como direcionam o preparo de seus concorrentes.

Tem-se como base teórica para análise o estudo das denominadas novas ameaças, tais como descritas nas conceituações de guerras que têm sido desenvolvidas com a evolução do pensamento estratégico, sendo as principais: guerras pós-modernas, guerra omnidimensional, guerra irrestrita, guerra de quarta geração (4GW) e guerra assimétrica. ${ }^{1}$ Exemplo emblemático de novas ameaças, as ações terroristas, na dimensão que tomou após

Humberto José Lourenção - Bacharel e licenciado em Filosofia (PUC/PR) e em Psicologia (UFPR); especialista em Filosofia da Educação (PUC/PR); MBA em Gestão Pública (FAAP); mestrado em Ciência Política (Unicamp) e doutorado em Ciências Sociais (Unicamp); pós-doutorado em Psicologia (USP); pós-doutorado em Ciências Militares na Escola de Comando e Estado-Maior do Exército (ECEME); research fellow at National Defense University (NDU); professor Associado III da Academia da Força Aérea (AFA); professor do quadro permanente do Mestrado em Ciências Aeroespaciais da Universidade da Força Aérea (UNIFA); pesquisador do Grupo de Estudos Forças Armadas e Política (UFSCar); Editor-chefe da Revista Defesa e Segurança (RDS). E-mail: lourencao@hotmail.com. CL: http://buscatextual.cnpq.br/buscatextual/visualizacv.do?id=K4707595A3.

Luis Eduardo Pombo Celles Cordeiro - Possui graduação em oficial aviador pela Academia da Força Aérea (AFA), e fez o Curso de Aperfeiçoamento de Oficiais da Aeronáutica. Mestrado em Ciências Aeroespaciais pela Universidade da Força Aérea (AFA). 
os ataques terroristas de 11 de setembro de 2001, define como eixo estratégico a guerra contra um inimigo supranacional, diluído por todo o planeta e razoavelmente invisível, posicionando-se tanto dentro como fora das fronteiras do Estado. No combate às novas ameaças já não se aplicam as grandes unidades de combate da ação militar clássica: pelotões, batalhões, brigadas, esquadrões, grupamentos, etc. Em vez delas, o combate é baseado em pequenos grupos de operações especiais; aqui o Estado não consegue usufruir de sua superioridade bélica, e encontra fortes dificuldades na imposição de uma derrota (Anderson, 2013).

A perda estatal do monopólio da guerra, trazendo em seu bojo novas ameaças à segurança internacional, compreende a mudança mais radical dentre as que vêm ocorrendo desde a Paz de Westphalia e serve para conceituar as denominadas guerras pós-modernas, guerras irregulares ou guerras de quarta geração (Lind, 2005). Nestas, as Forças Armadas (FFAA) passam a combater oponentes não estatais, tais como a al-Qaeda, o Hamas, a Hezbollah, as Forças Armadas Revolucionárias da Colômbia (FARC), o Estado Islâmico, etc., que não seguem as convenções de Haia ${ }^{2}$ e cujos combatentes apresentam poucas diferenças entre civis e soldados. A guerra pós-moderna volta a um mundo de choque entre culturas, pré-westphaliano, e não meramente de países em conflito; assim, a invasão de imigrantes pode ser tão securitizada quanto a invasão de um exército inimigo, fazendo prevalecer os conflitos de baixa intensidade.

Neste cenário, uma vitória no nível bélico, tático, não necessariamente vem acompanhada de vitória no nível estratégico, moral e psicológico, onde se decide o novo modelo de guerra. Trata-se de um contexto de valorização da denominada Inteligência Cultural, em que o combatente, além de possuir as habilidades sociointerativas para se integrar à comunidade local, sob o slogan "tirando o capacete assim que possível”, é capaz de analisar, sobre o prisma do choque intercultural, como está sendo travada a guerra por legitimidade. Mais importante de que identificar como o inimigo combate, é saber quem está lutando, para quê e sob quais motivos (Visacro 2009).

\section{EVOLUÇÃO DA TEORIA E DO EMPREGO DA FORÇA DOS ESTADOS UNIDOS NO PERÍODO FINAL DA GUERRA FRIA}

Ao longo dos anos 1980 ocorreram mudanças significativas na estrutura e na doutrina militar das Forças Armadas norte-americanas, baseadas principalmente nos ensinamentos extraídos da Guerra no Vietnã (1959-1975). Dentre essas mudanças, estão: a profissionalização do efetivo, ou seja, a criação de uma força de voluntários no lugar da conscrição, 
avanços na tecnologia militar e no treinamento das tropas, surgimento das Forças Especiais Delta do Exército, elaboração da doutrina Weinberger, ampla reforma no Departamento de Defesa e desenvolvimento de novas teorias do poder aéreo (Kagan 2006). Percebe-se que o foco era modificar a maneira de lutar, mas que o inimigo ainda era percebido como uma entidade política existente no Sistema Internacional, ou seja, o cálculo de força considerava uma ameaça estatal em uma guerra entre Estados com o uso da violência como um recurso para imposição da vontade. Tais doutrinas puderam ser percebidas nas invasões de Granada e do Panamá.

Acerca dos avanços na tecnologia militar, a doutrina de retaliação maciça adotada na administração de Dwight Eisenhower (1953-1961) baseada na centralidade das armas nucleares foi superada pelo conceito de "Energy Maneuverability" (Maneabilidade de Energia) de John Boyd, que rejeitava a ideia de priorizar um único tipo de guerra, a nuclear. Isso ocorreu durante o governo do presidente John F. Kennedy, convicto de que a retaliação maciça aumentava a possibilidade de uma guerra convencional, não desejável em razão da situação de MAD - "Mutual Assured Destruction” (Destruição Mútua Assegurada) de agressor e defensor. Assim, ela foi substituída por uma abordagem considerada mais maleável, denominada resposta flexível. Complementarmente, partindo da ideia de que forças inimigas podem ser derrotadas através de ataques em suas comunicações, nos anos 1980 Boyd, formulou uma teoria que defendia a destruição das conexões entre os centros OODA (Observação, orientação, decisão e ação), tornando-os não cooperativos, o que limitaria as ações do inimigo (Coram 2002).

Nessa linha de raciocínio de ênfase na flexibilidade, para Boyd, o que habilitava um piloto a manobrar melhor que o adversário não era a velocidade nem a potência, mas sim seu nível de flexibilidade. Inspirado por este conceito o grupo denominado "Fighter Mafia" (Máfia dos Caças) desenvolveu o F/A-18 Hornet, um caça multitarefa, habilitado a lutar muitos tipos de conflitos contra distintos inimigos. Além disso, a Força Aérea americana também adotou a doutrina DOC - "Designed Operational Capability" (Capacidade Operacional Planejada) -, segundo a qual esquadrões específicos podiam desempenhar diferentes missões aéreas (Coram 2002).

Simultaneamente, o Exército procurou desenvolver carros de combate menores, mais leves e rápidos. Para isso, a propulsão passou a ser a gás e um novo tipo de blindagem mais leve, denominada Chobham, foi adotada (Kagan 2006). Com relação à Doutrina, o "US TRADOC - Army Training and Doctrine Command" (Comando de Doutrina e Treinamento do Exército) desenvolveu a chamada Defesa Ativa, baseada na antecipação, objetivando se preparar para ganhar a primeira batalha da próxima 
guerra. Outra doutrina desenvolvida neste período, chamada Batalha Aéreo-Terrestre, tinha a virtude de não ser específica para o teatro de operações de características europeias, até então o foco norte-americano da Guerra Fria, prevenindo uma invasão terrestre soviética naquele continente (Kagan 2006).

A administração do presidente Ronald Reagan (1981-1989) desenvolveu a SDI - "Strategic Defense Initiative" (Iniciativa Estratégica de Defesa)-, também conhecida como Guerra nas estrelas, centrada em um escudo antimíssil a ser usado contra ataques soviéticos, aumentando em um terço os gastos de defesa entre 1981 e 1989. O republicano Caspar Weinberger, Secretário de Defesa do governo Reagan entre janeiro de 1981 e novembro de 1987, desempenhou importante papel na Iniciativa, enfocando na defesa ao invés do ataque, ainda considerando o contexto de MAD (Kagan 2006). Segundo a denominada Doutrina Weinberger, os Estados Unidos deveriam estar preparados, em qualquer momento, para lidar com ameaças de diferentes intensidades: de atos terroristas isolados, passando por ações de guerrilha até a confrontação militar maciça. Para isto, a relação entre objetivos e desenho de força (tamanho, composição e disposição) deve ser continuamente reajustada (Weinberger 1984).

A partir de 1986 ocorreu uma substancial mudança no Departamento de Defesa dos Estados Unidos, resultado da implantação da "Goldwater-Nichols Defense Reorganization Act" (Lei Goldwater-Nichols de Reorganização da Defesa), de 1986 - elaboradas pelos senadores Barry Goldwater (republicano) e William Flynt Nichols (democrata) - acrescida da "Cohen-Nunn Amendment" (Emenda Cohen-Nunn), de 1987. Esses dispositivos legais significaram o fim da independência das Forças singulares, isto é, Exército, Marinha, Aeronáutica e Marines (fuzileiros navais), fortalecendo o papel do Estado-Maior Conjunto. A Emenda Cohen-Nunn reorganizou as Forças de Operações Especiais, reunindo-as sob o SOCOM - "Special Operations Command" (Comando de Operações Especiais). Assim, as Forças Especiais estariam subordinadas aos comandantes das regiões somente quando operando no território geográfico correspondente; por seu turno, o SOCOM controlaria o orçamento, o treinamento e a doutrina de todas as Forças de Operações Especiais (Quinn 1999).

Neste período, uma importante contribuição à teoria da guerra foi trazida por John Warden III, quando publicou seu livro "The Air Campaign" (A Campanha Aérea), em 1989, no qual desenvolveu a tese de que a superioridade aérea é tão fundamental para a vitória nas guerras atuais que todas as demais operações devem estar direcionadas a alcançá-la. Tal teoria foi amplamente utilizada na Primeira Guerra do Golfo, em 1991. Warden identifica cinco anéis estratégicos do inimigo: liderança, produção indus- 
trial, infraestrutura, população e forças armadas. Assim, ele sugere a ideia de "Assauting the Air Center of Gravity" (Assalto ao centro de gravidade aéreo), através de ataques simultâneos realizados de dentro para fora dos cinco anéis, que desmontaria o sistema inimigo sem ter que enfrentá-lo diretamente. Isso geraria uma paralisia estratégica, impossibilitando a capacidade de reação do inimigo, através da neutralização parcial ou total da sua capacidade de comando (Warden III 1989).

\section{DO FIM DA GUERRA FRIA AO 11 DE SETEMBRO DE 2001}

Com o fim da Guerra Fria, estabelecido a partir da queda do muro de Berlim (1989) e do desmantelamento da União Soviética (1991), havia a crença que os Estados Unidos poderiam usufruir de um período de paz que resultasse em Forças Armadas reduzidas e menor orçamento de defesa. Particularmente após a $1^{\mathrm{a}}$ Guerra do Golfo, de 1991, os Estados Unidos emergiram como uma superpotência hegemônica, que lideraria uma nova ordem mundial alicerçada na democracia liberal (Kagan 2006). Sem adversários diretos e possuidor de uma força militar sem concorrentes, os EUA focaram nos subatores estatais e na cooperação como doutrina de emprego.

Nessa linha, Colin Powell, chefe do Estado-Maior Conjunto das Forças Armadas dos Estados Unidos entre 1989 e 1993, delineou uma nova estratégia militar, que ficou posteriormente conhecida como Doutrina Powell, tendo como premissa que a instabilidade política mundial tende a crescer após a queda de impérios (como recém ocorrera com o soviético). A nova estratégia dos Estados Unidos teria que focar em contingências regionais, em substituição ao foco anterior em uma guerra global contra a URSS, devendo suas Forças Armadas ser capazes de conduzir um vasto número de missões e lidar com várias ameaças simultaneamente. Segundo a Doutrina Powell, a ação militar só deve ser usada quando receber um prévio apoio por parte da opinião pública e sempre com vantagem desproporcional à inimiga (Powell 1992). Este último elemento representou uma guinada na política de proporcionalidade até então adotada pelos Estados Unidos para evitar a escalada da guerra.

A Guerra do Golfo (1990-1991), rápida e vitoriosa, constitui um bom exemplo do emprego da Doutrina Powell. Para suplantar o então quarto maior exército do mundo em menos de uma semana, os Estados Unidos utilizaram simultaneamente todas as expressões de Poder Nacional contidas no conceito DIME - "Diplomatic, Information, Military and Economic" (Diplomacia, Informação, Força Militar e Poder Econômico). Seis meses antes do início do emprego da força, uma ampla campanha de mídia contra a imagem de Saddam Hussein contribuiu para que sanções econômicas e 
militares fossem aprovadas por unanimidade pelo Conselho de Segurança da ONU e pela Liga dos Países Árabes, bem como o envio de tropas americanas para a região. Assim, de agosto de 1990 a janeiro de 1991 o Iraque ficou isolado diplomática e economicamente, resultando em acentuado enfraquecimento das expressões do Poder Nacional iraquianas antes mesmo que qualquer tiro fosse disparado ou bomba fosse lançada (Kelly 1996). Assim, pode-se afirmar que, pelo menos desde a Guerra do Golfo de 1990, os Estados Unidos já questionavam a utilização do poder militar como única fonte de instrumento de poder e observa-se no desenvolvimento do conceito DIME que a utilização do denominado "soft power" gerou mudanças na própria doutrina de defesa dos EUA (Hillson 2009)

$\mathrm{Na}$ administração de Bill Clinton (1993-2001), partindo do pressuposto de que a guerra não seria mais uma ameaça sistêmica como foi na época da bipolaridade EUA-URSS, a formulação da segurança nacional deveria priorizar novos temas, como os Direitos Humanos e as relações comerciais. A “Central Intelligence Agency” - CIA (Agência Central de Inteligência) - recebeu a orientação para focar na inteligência econômica em detrimento da espionagem político-militar (Taylor 2007).

O então Secretário de Defesa Leslie Aspin iniciou um processo denominado BUR - "Bottoms-Up Review” (Revisão de baixo para cima) -, com o propósito de repensar cada aspecto da política militar americana. Essa revisão chegou a duas conclusões principais: o principal interesse norte-americano era a expansão global da prosperidade econômica, portanto, a força militar deveria atuar no sentido de manter a estabilidade mundial; para continuar projetando poder em vários pontos do globo, as Forças Armadas dos Estados Unidos deveriam se tornar mais leves, rápidas e ágeis, apoiadas por tecnologia de ponta (Friedman 2004).

As forças singulares americanas tiveram reações contrastantes diante do BUR: enquanto a Força Aérea e o Comando de Operações Especiais aprovaram, pois perceberam a oportunidade de receber maior aporte tecnológico, o Exército, por sua vez, interpretou como uma diminuição de sua importância. Reflexos dessas medidas puderam ser sentidos na invasão do Afeganistão, menos de uma década depois. A Força Aérea dos Estados Unidos passou a trabalhar com o conceito de "Global Reach" (Alcance Global), segundo o qual a força poderia acertar alvos a partir de bases localizadas no território dos EUA, usando bombardeiros de longa distância, sem a necessidade de manter navios ao redor do mundo ou de envio prévio de aviões táticos. Neste novo modelo, o poder de fogo pesado viria antes e mais dos aviões, do que da artilharia e dos tanques. Por sua vez, as forças de combate de solo, organizadas em Forças de Operações Especiais em vez de exército convencional, seriam mais leves e rápidas, além de usarem tecno- 
logias mais sofisticadas. Na necessidade de maiores forças terrestres, estas poderiam ser recrutadas nas forças locais, sendo, posteriormente, treinadas e guiadas pelas Forças Especiais do Exército (Friedman 2004). Como resultado do BUR, os Estados Unidos enxugaram suas Forças Armadas, mantendo a capacidade de conduzir duas guerras simultaneamente, ou seja, dois "Major Regional Conflicts" (MRCs) ao mesmo tempo, como ocorreu recentemente no Iraque e no Afeganistão (Kagan 2006).

Ainda na década de 1990 e reforçando a tendência liberal empregada, os EUA desenvolveram o conceito de MOOTW - "Military Operations other than War" (Operações Militares outras que a Guerra) (Lourenção 2017). O foco do MOOTW está em ações antiterroristas, medidas defensivas para reduzir a vulnerabilidade a atos terroristas, e em ações de contraterrorismo, medidas ofensivas para prevenir, dissuadir e responder a atos terroristas, incluindo o apoio a governos e autoridades civis nos casos de crises domésticas. Em uma MOOTW, pode ocorrer dos militares empregados não serem os protagonistas da operação (DTIC 1995).

Nesse período, imbuídos da ideia de que uma era da informação estaria substituindo a era industrial, muito difundida na época, o Exército americano adotou o "Dominant Battlespace Knowledge" (Conhecimento dominante do espaço de batalha), um programa oriundo do setor de negócios que visava o aumento da eficiência por meio do uso da tecnologia da informação (Kagan 2006). Avançando nesta abordagem, em 1996 surgiu a teoria da NCW - "Network Centric Warfare" (Guerra centrada em rede) -, também oriunda do mundo dos negócios, que, em essência, visava transformar a superioridade de informações em poder de combate, através da interligação de todas as fontes que detêm algum tipo de conhecimento relevante acerca do espaço de batalha (Alberts 1996).

\section{A GUERRA A PARTIR DE 11 DE SETEMBRO DE 2001}

Os ataques terroristas ocorridos em território norte-americano em setembro de 2001 consagraram a prevalência atual dos conflitos entre uma força estatal e grupos irregulares subestatais, conhecidos por "low-intensity conflicts" (conflitos de baixa-intensidade) ou "small wars" (pequenas guerras), que podem ser tão violentos quanto uma guerra convencional (Gray 2006).

Durante a gestão de Donald Rumsfeld, Secretário de Defesa entre 2001 e 2006, particularmente após os atentados terroristas sofridos em 11 de setembro de 2001, houve a introdução nas Forças Armadas dos Estados Unidos do conceito de "Shock and Awe" (Choque e Pavor), demarcando uma evolução tática sobre o conceito "Hammer and Anvil" (Martelo e bi- 
gorna $)^{3}$ e consolidando a tendência para as denominadas "operações cirúrgicas", de alta precisão. ${ }^{4}$ Segundo o conceito "Shock and Awe”, também conhecido por "Rapid Dominance” (Domínio rápido), um ataque deve ter um poderio físico tamanho de modo que o inimigo se sinta psicologicamente tão vulnerável e intimidado que o demova de qualquer resistência (Ullman e Wade 1996).

Assim, a estratégia militar de Rumsfeld definia que as Forças Armadas americanas, além das responsabilidades de defender o território norte-americano e o de seus aliados e de vencer qualquer "major conflict" (conflito principal), deveriam ser capazes também de conduzir simultaneamente algumas operações de pequena escala em diferentes partes do mundo (Herspring 2008).

Desde então, endossada pela publicação da Estratégia de Segurança Nacional dos Estados Unidos de 2002, consolidou-se a convicção de que grupos terroristas constituem uma enorme ameaça aos Estados Unidos e à sociedade civilizada, devendo ser eliminados por não serem considerados passíveis de serem apaziguados ou coibidos (USA 2002). Com efeito, uma sensação generalizada de insegurança passou a predominar no interior da sociedade norte-americana, justificando medidas governamentais restritivas às liberdades civis e ofensivas aos direitos humanos de prisioneiros, desgastando a legitimidade norte-americana no sistema internacional. No nível externo, houve o incremento de ações militares preemptivas, ocorrendo a aplicação pró-ativa da força de modo a incapacitar um presumível inimigo, mesmo na falta de elementos que comprovassem a ameaça, exemplificada pela última intervenção no Iraque iniciada em março de 2003, exemplo da dualidade do discurso liberal por uma cooperação internacional para combate ao terror e da ação realista de invasão de outro Estado.

Anteriormente ao Iraque, os Estados Unidos empreenderam uma ação militar no Afeganistão denominada OEF - "Operation Enduring Freedom" (Operação Liberdade Duradoura), a partir de outubro de 2001, com o objetivo de atacar a al-Qaeda, responsabilizada pelo atentado, e remover o regime Talibã naquele país. Um ponto inovador dessa ação foi o papel de liderança conferido à CIA, dado que o Pentágono não desenvolvera um plano para desenvolver operações convencionais em terreno afegão, enquanto a agência central de inteligência possuía consideráveis conhecimentos da região, da cultura e, principalmente a respeito de quais grupos étnicos seriam cooperativos e quais não seriam. Outro ponto inovador foi o uso de uma força nativa local, a Aliança Norte, reforçada com Forças de Operações Especiais, equipes da CIA e apoio aéreo provido pelo US "Central Command" CENTCOM (Comando Central) -, que é o comando responsável pelas relações e operações militares nessa região (Herspring 2008). 
A ação no Afeganistão resultou no aumento do status do SOCOM que, sob a administração Rumsfeld, foi expandido e angariou autonomia dos comandos regionais, com maior autoridade para planejar e lutar a guerra global contra o terror (Herspring 2008). O DoD - "Department of Defense" (Ministério da Defesa) - americano convenceu-se de que unidades menores compostas de pessoal altamente treinado seriam mais efetivas do que as forças convencionais como tanques e veículos blindados. Dessa época em diante consolidou-se a tendência de diminuir o tamanho das Forças Armadas dos Estados Unidos, tornando-as mais leves e ágeis.

Essa tendência acentuou-se na gestão do sucessor de Rumsfeld, Robert Gates, Secretário de Defesa entre 2006 e 2011, que continuou a priorizar o emprego das Forças de Operações Especiais ("Delta Force", "Rangers", "Navy Seals", MSOR - "Marine Special Operations Regiment", etc.), reduzindo a participação das forças convencionais (Kaplan 2006). Na gestão Gates, em meados de 2008, houve a publicação do documento governamental "National Defense Strategy" (Estratégia de Defesa Nacional) que, expressando no nível retórico o que já estava ocorrendo na prática, enfocava mais em guerra irregular contra grupos terroristas do que em guerras convencionais, tipicamente investidas contra estados nacionais (USA 2008). Igualmente o documento "Sustaining U.S. Global Leadership: Priorities for 21 st Century Defense” (Sustentando a liderança global dos Estados Unidos: prioridades para a defesa do século XXI) (USA 2012), publicado sob a gestão do Secretário de Defesa Leon Panetta (2011-2013), subsequente a Gates, prosseguiu com o modelo de manutenção da superioridade militar com forças armadas menores, com maior prontidão e flexibilidade. $\mathrm{O}$ documento enumerou as prioridades das Forças Armadas americanas como sendo, entre outras: contenção de terrorismo e de armas de destruição de massa, operações no ciberespaço, manutenção de uma efetiva deterrência nuclear, condução de operações e de contrainsurgência e de missões humanitárias (USA 2012).

Em relação à macroestratégia, após mais de uma década de conflitos, a Estratégia Nacional de Defesa dos EUA de 2015 explicita que o uso da força não deve ser a única nem a primeira opção empregada para resolução de conflitos interestatais. Ressalta também a necessidade de operações conjuntas com aliados para minimizar possíveis desconfianças e aumentar a percepção dos EUA como um aliado no combate, não somente às ameaças de segurança, mas também em outras áreas, como mudanças climáticas e epidemias de saúde (USA 2015). Identifica-se assim o esgotamento do modelo realista de ações individuais, sai de cena o infante "boots on the ground”, ou seja, aquele que opera diretamente no combate, e passa-se a 
priorizar a utilização de aeronaves (tripuladas ou não) e de assessores militares que passam conhecimento e armamento para as tropas locais.

Sobre a condução de missões humanitárias, ela passou a receber maior consideração com o desenvolvimento da doutrina PIMESII ("Political, Military, Economic, Social, Information and Infrastructure”), que enfocam o emprego da força militar de ajuda humanitária, ações cívico-sociais, socorro em calamidades, etc., no afã de conquistar corações e mentes da população-alvo. Essa maior consideração advém do fato de que atualmente o acesso a tecnologias pode fazer com que ações individuais possam representar uma ameaça real ao Estado; ameaças que, antes da era da informação, só se originavam de outros Estados e/ou de grupos insurgentes ou terroristas. Os terroristas denominados lobos-solitários são uma tendência crescente hoje em dia e outras ameaças podem provir de qualquer indivíduo do planeta com acesso à internet, o que capilariza sensivelmente os potenciais inimigos. Daí a necessidade da doutrina PIMESII, para medir os efeitos da ação humanitária na moral da população em foco (GEIS II et al. 2014).

\section{CONCLUSÃO}

Com base nos dados acima, pode-se concluir que as transformações ocorridas no modo dos EUA de conduzir suas guerras, principalmente a partir do 11 de setembro, resultaram de uma reorganização burocrática no organograma do sistema de defesa, sempre amparadas na introdução de novas tecnologias e sistemas de armas. De fato, o foco em grupos de operações especiais, em tropas mais enxutas e no aprofundamento da profissionalização militar inspirou novas táticas de guerra.

Entretanto, tais transformações no modo de conduzir as guerras têm sido muito insuficientes para o alcance mais amplo de seus propósitos. Pode-se afirmar que os EUA têm ganhado as batalhas em que se meteu recentemente, mas estão perdendo as guerras pós-modernas. São vitórias muito insatisfatórias na medida em que ocorrem só a nível militar, indo na contramão do atual pensamento estratégico, que fundamenta a importância dos aspectos psicossociais de uma batalha. Apesar desses elementos estarem presentes no discurso do próprio governo norte-americano, eles ainda não foram incorporados nas práticas de guerra. Dessa forma, as campanhas empreendidas após o 11 de setembro representam vitórias militares inequívocas, mas são descuidadas de um acompanhamento mais responsável com os povos que habitam os teatros de operações. Esse descuido tem deixado para trás mais mágoa e sentimento de iniquidade do que deixaria se houvesse uma atenção maior aos aspectos não militares de 
toda batalha. Consequentemente observa-se o crescimento do antiamericanismo, expresso em discursos odiosos e em práticas terroristas contra os Estados Unidos e seus aliados, não obstante os grandes esforços propagandísticos em contê-lo.

Os Estados Unidos ainda não estão conscientes do quanto as mudanças táticas são insuficientes no contexto do pensamento estratégico que embasa as guerras pós-modernas, segundo o qual a vitória na área militar é muito pouco perto dos desafios maiores de conquistar corações e mentes que visem sedimentar uma paz mais duradoura para cada contexto; à vitória na esfera militar devem-se somar vitórias na área diplomática, econômica e de informações, dentro do conceito DIME. Para além do uso de táticas inovadoras e otimização das campanhas que miram nos centros de gravidades do inimigo com o mínimo de baixas próprias, é necessário ampliar o escopo de atuação cívico-social-humanitária, objetivando vitórias morais, tanto no âmbito da política interna como na externa.

\section{REFERÊNCIAS}

Alberts, D. S. 1996. Information age transformation: getting to a 21 st century military. Washington: CCRP.

ANDERSON, G. 2013. The End of the Peace of Westphalia: Fourth Generation Warfare. Small Wars Journal. Disponível em: <http://smallwarsjournal.com/jrnl/ $\mathrm{art} /$ the-end-of-the-peace-of-westphalia-fourth-generation-warfare $>$. Acesso em: 27 Out 2015.

Coram, R. B. 2002. The Fighter Pilot Who Changed the Art of War. New York: Back Bay Books.

DTIC - Defense Technical Information Center. 1995. Joint Doctrine. MOOTW Military Operations other than War. Disponível em: <http://www.dtic.mil/doctrine/jrm/mootw.pdf $>$. Acesso em: 29 set. 2013.

Friedman, G. 2004. America's Secret War: Inside the Hidden Worldwide Struggle between America and Its Enemies. New York: Broadway Books.

Geis II, J. P., Hammond, G. T., Foster, H. A., Hailes, T. C. 2014. Blue Horizons IV Deterrence in the Age of Surprise. Alabama: Air University Press.

Gray, C. S. 2006. Irregular Enemies and the Essence of Strategy: Can the American Way of War Adapt? U.S. Army War College; Strategic Studies Institute. Disponível em: $<$ http://www.strategicstudiesinstitute.army.mil/pubs/download.cfm?q=650>. Acesso em: 17 mar. 2014. 
Herspring, D. R. 2008. Rumsfeld's Wars: The Arrogance of Power. Kansas: University Press of Kansas.

Hillson, R. 2009. DIME/PMESII Requirements Project. Disponível em: <www.dtic. $\mathrm{mil} /$ cgi-bin/GetTRDoc?AD=ADA525056>. Acesso em: 18 out. 2015.

Kagan, F. W. 2006. Finding the Target: The Transformation of American Military Policy. New York: Encounter Books.

Kelly, T. W. 1996. Iraq went from the fourth-largest army in the world to the second-largest army in Iraq in 100 hours. Disponível em: <http://www.arlingtoncemetery.net/ twkelly.htm>. Acesso em: 01 mar. 2014.

LIND, W. S. 2005. "Compreendendo a Guerra de Quarta Geração", Military Review, 85, (3), 12-17.

Lourenção, H. J. 2017. Recent Agreements between Brazil and the US. In: Ricco, M. F. F. (Org.). Culture and Defence in Brazil. New York: Routledge.

Lourenção, H. J., Cordeiro, L. E. P. C. 2016. Análise do Emprego da Força Militar pelos EUA no Período Pós-Guerra Fria à Luz dos Conceitos de Guerras Pós-Modernas. Revista da Escola de Guerra Naval, 22 (3), 643-656.

Powell, C. L. 1992. U.S. Forces: Challenges ahead. Disponível em: <https://www. foreignaffairs.com/articles/1992-12-01/us-forces-challenges-ahead>. Acesso em 03 mar. 2014.

Quinn, D. J. 1999. The Goldwater-Nichols DOD Reorganization Act: a ten -year retrospective. Washington: National Defense University Press.

Taylor, S. A. 2007. The Role of Intelligence in National Security. In: Collins, A. (Coord.). Contemporary Security Studies. Oxford: Oxford University Press.

Ullman, H. K., Wade, J. P. 1996. Shock And Awe: Achieving Rapid Dominance. Washington: National Defense University.

USA - United States of America. National Security Council. 2002. The National Security Strategy of the United States of America. Disponível em: <http://www.usa. gov/nsc/nss.html>. Acesso em: 29 set. 2013.

USA. Department of Defense. 2012. Sustaining U.S. Global Leadership: Priorities for 21 st Century Defense. Disponível em: <http://www.defense.gov/news/defense_ strategic_guidance.pdf>. Acesso em: 28 mar. 2013.

USA. Department of Defense. 2008. National Defense Strategy. Disponível em: $<$ http://www.defense.gov/news/2008_national_defense_strategy.pdf $>$. Acesso em: 28 mar. 2013. 
USA. The White House. 2015. National Security Strategy. Disponível em: < https:// www.whitehouse.gov/sites/default/files/docs/2015_national_security_strategy. pdf $>$. Acesso em: 18 out. 2015.

VISACRO, A. 2009. "Guerra Irregular: Terrorismo, Guerrilha e Movimentos de Resistência ao Longo da História”. São Paulo: Contexto.

Warden III, J. A. 1989. The Air Campaign: planning for combat. 1. ed. McLean: Pergamon-Brassey's.

Weinberger, C. W. 1984. The Uses of Military Power. Washington: National Press Club. Disponível em: <http://www.pbs.org/wgbh/pages/frontline/shows/military/force/weinberger.html>. Acesso em: 25 jan. 2014. 


\section{NOTAS}

1. Uma descrição pormenorizada da evolução do pensamento estratégico sobre o estudo das guerras encontra-se em Lourenção, H. J.; Cordeiro, L. E. P. C. 2016. Análise do Emprego da Força Militar pelos EUA no Período Pós-Guerra Fria à Luz dos Conceitos de Guerras Pós-Modernas. Revista da Escola de Guerra Naval, 22 (3), 643-656.

2. Regras e normas que disciplinam o comportamento estatal durante as guerras foram definidas pelas convenções de Haia dos anos de 1860, 1899, 1907 e 1949, entre outras: são proibidos certos tipos de armas, como, por exemplo, armas biológicas; é proibido tomar civis como reféns; há regulamentações que regem o tratamento de soldados capturados ou que se renderam (prisioneiros de guerra); reconhece-se território neutro; permite-se acesso para atendimento de feridos; defende-se a inviolabilidade de diplomatas e outros representantes credenciados.

3. A tática de martelo e bigorna remonta a época das campanhas militares de Alexandre da Macedônia, em que uma parte da tropa segura o inimigo, fazendo o papel de bigorna enquanto a outra golpeia, martelo, espremendo o inimigo entre elas. No caso dos Estados Unidos, as tropas de solo eram a bigorna e o poder aéreo o martelo.

4. A capacidade para as operações cirúrgicas se baseou em dois tipos de armamentos inteligentes: as JDAM - Joint Direct Attack Munitions (Munições conjuntas para ataque direto) - guiadas por satélite, e os CALCM - Conventional Air Launched Cruise Missile (Mísseis de cruzeiro convencionais lançados do ar) -, que utilizam o GPS - Global Positioning System (Sistema de Posicionamento Global) - para navegar e localizar seus alvos com precisão, permitindo serem operados em qualquer condição de tempo. 
FORÇA MILITAR DOS EUA NO PÓS-GUERRA FRIA:

GANHANDO BATALHAS E PERDENDO GUERRAS

\section{RESUMO}

Este texto analisa as campanhas de emprego de força militar que os Estados Unidos da América (EUA) empreenderam entre o término da Guerra Fria e os dias atuais, à luz dos conceitos de novas ameaças. A posição militar hegemônica estadunidense inspira um grande número de atores presentes no cenário internacional, justificando assim uma análise sobre os resultados obtidos. O emprego crescente de forças especiais no período analisado constitui a tônica da evolução do emprego da força por parte dos EUA. Entretanto, pode-se afirmar que os EUA têm ganhado as batalhas em que se meteu recentemente, mas estão perdendo as guerras pós-modernas. São vitórias muito insatisfatórias na medida em que ocorrem só a nível militar, indo na contramão do atual pensamento estratégico que fundamenta a importância dos aspectos psicossociais de uma batalha. Apesar desses elementos estarem presentes no discurso do próprio governo norte-americano, eles ainda não foram incorporados nas práticas de guerra.

Palavras-chaves: Guerra; Guerras Pós-Modernas; EUA.

\section{ABSTRACT}

This paper analyzes the military employment campaigns that the United States of America has undertaken between the end of the Cold War and today, in the light of the concepts of new threats. The US hegemonic military position inspires a large number of actors present on the international scene, thus justifying an analysis of the results obtained. The increasing use of special forces in the period under review is the key to the evolution of US employment by force. However, it can be said that the US has won the battles it has recently entered but are losing postmodern wars. They are very unsatisfactory victories insofar as they occur only on a military level, going against the current strategic thinking that underlies the importance of the psychosocial aspects of a battle. Although these elements are present in the US government's own discourse, they have not yet been incorporated into the practices of war.

Keywords: Warfare; Postmodern Wars; USA.

Recebido em 04/04/2017. Aceito para publicação em 25/06/2017. 